\title{
The Influence of Deformity and Limited Joint Mobility on Foot Ulceration in Type 2 Diabetes
}

\author{
Josephine Debattista, Alfred Gatt* and Cynthia Formosa \\ Podiatry Department, Faculty of Health Sciences, University of Malta, Malta \\ *Corresponding Author: Alfred Gatt, Podiatry Department, Faculty of Health \\ Sciences, University of Malta, Malta.
}

Received: August 21, 2021

Published: September 18, 2021

(C) All rights are reserved by Alfred Gatt., et

al.

\begin{abstract}
Aim: To investigate the influence of foot deformities on diabetes foot ulcer development.

Methods: Two groups of $n=50$ participants were recruited; Group A with current and/or history of foot ulceration, Group B matched for main confounding variables, without ulcers. A comprehensive clinical and biomechanical examination was performed to record foot deformities, together with foot joint range of motion.

Results: $68 \%$ of ulcers in Group A were located in the toes, with the apex of the $2^{\text {nd }}$ toe being the commonest site of ulceration (26\%), whilst $32 \%$ of the ulcers were located under the $1^{\text {st }}(20 \%)$ and $5^{\text {th }}(12 \%)$ metatarsophalangeal joints. Group A exhibited significantly more foot deformities than Group B, including hammer, claw and mallet toe deformities, limitation in joint mobility at the joints, including the ankle, subtalar, midtarsal, first ray and first metatarsophalangeal joint. Prominent metatarsophalangeal joints were also more common in Group A (60 - 66\%; p < 0.001).

Conclusion: Toe deformities, which may often be considered as insignificant in clinical practice, are an important aspect that need to be managed well in patients living with diabetes mellitus in order to try to prevent the onset of ulceration. Methods to improve joint motion should also be advised to patients at risk.
\end{abstract}

Keywords: Diabetes Mellitus; Diabetic Foot Ulceration; Foot Deformities

\section{Introduction}

Although diabetes mellitus is known to result in negative repercussions on one's health and quality of life if not well monitored and managed [1], foot ulceration remains one of the main complications, affecting $15 \%$ to $25 \%$ [2] of persons living with this condition. Foot ulcerations are very common complications that can develop with trauma to the skin in the high-risk foot [3]. However, although amongst other risk factors, foot deformities and limited joint mobility are known to be risk factors for ulceration [4], not enough emphasis is given to recommendations for the assessment of these conditions in all screening guidelines [5]; on the other hand, those guidelines that do include a recommendation for the evaluation of existing foot deformities, support their recommendations by low quality evidence.

Several studies have documented that people living with Type II diabetes and foot deformities have an increased risk of foot ulceration [6-10]. In fact, a strong association between ulceration and foot deformities such as hammer/claw toes and hallux limitus has been reported [8].

However, there is still not enough evidence to ascertain that certain foot types cause more risk of ulcer development [11]. Consequently, more evidence is required in order to demonstrate whether foot deformities and foot types lead to foot ulcerations [8,10,12]. 


\section{Aim of the Study}

Thus, the aim of this study was to determine the influence of foot posture and foot deformity on foot ulceration in type 2 diabetes.

\section{Method}

Following ethical approval by the University Research Ethics Committee, a prospective, comparative non-experimental design study was held with 100 subjects recruited from an Endocrinology Outpatient clinic at a general hospital. All subjects were treated according to the Treaty of Helsinki.

For the purpose of this study, convenience sampling was adopted. Subjects of 45years of age or older living with Type II Diabetes Mellitus. Those with any type of lower limb amputation, no ambulatory status, those diagnosed with Charcot feet, and expressing an unwillingness or inability to participate were excluded.

The first 50 consecutive patients presenting with a foot ulcer were invited to participate in this study. Another 50 patients without a foot ulcer who fulfilled the inclusion criteria were also recruited to act as controls. Thus participants were divided two groups: 50 with presence and/or history of foot ulceration (Group A) and 50 subjects with no present and/or history of ulceration (Group B). Precision matching and frequency distribution matching methods were utilized to have an equal representation of all relevant factors and to ensure that there were no other confounding variables known to be associated with formation of ulceration. Subjects were matched using frequency distribution matching of $+/-5$ years for age, duration of diabetes and HBA $1_{c}$. Precision matching was used for mode of medication and gender.

In this study, deformities included hammer toes, claw toes, hallux abuducto valgus (HAV), hallux limitus and prominent metatarsals [13]. Range of motion (ROM) of foot joints were also assessed in order to determine the extent of limitation of joint mobility in both groups.

Definitions for deformities as used throughout this study are presented in table 1.

\section{Protocol}

All subjects underwent the same procedure. Data recorded included details of the duration of diabetes and the and site of ulcer-

\begin{tabular}{|c|c|}
\hline Term & Definition \\
\hline Hammer toe & $\begin{array}{l}\text { Having a combination of metatarsophalangeal } \\
\text { extension and proximal interphalangeal flexion } \\
\text { [17] }\end{array}$ \\
\hline Claw toe & $\begin{array}{l}\text { Extension of the metatarsophalangeal joint and } \\
\text { flexion of the proximal and distal interphalan- } \\
\text { geal joints [18] }\end{array}$ \\
\hline Mallet toe & $\begin{array}{l}\text { Having a contractive distal interphalangeal joint } \\
\text { in which the phalanx is flexed on the middle } \\
\text { phalanx [19] }\end{array}$ \\
\hline HAV & $\begin{array}{l}\text { Hallux is deviated towards the lateral side of } \\
\text { the foot with a prominence developed over the } \\
\text { medial side of the first metatarsal head which is } \\
\text { usually categorized using the Manchester Scale } \\
\text { [14] }\end{array}$ \\
\hline $\begin{array}{l}\text { Hallux } \\
\text { rigidus }\end{array}$ & $\begin{array}{l}\text { Which is defined as having severely limited dor- } \\
\text { siflexion of the first metatarsophalangeal joint } \\
\text { of less than } 40^{\circ} \text { to none at all [13] }\end{array}$ \\
\hline $\begin{array}{l}\text { Hallux } \\
\text { limitus }\end{array}$ & $\begin{array}{l}\text { Involves having limited range of motion within } \\
\text { the 1st metatarsal phalangeal joint of less than } \\
\qquad 55^{\circ}[20]\end{array}$ \\
\hline $\begin{array}{l}\text { Limited first } \\
\text { ray }\end{array}$ & $\begin{array}{l}\text { Calculated as having }<1 \mathrm{~cm} \text { in dorsiflexion and } \\
\text { plantarflexion movement [21]. The position of } \\
\text { the } 1 \text { st ray is also noted in relation to the } 2 \mathrm{nd} \text { to } \\
\text { 5th rays }\end{array}$ \\
\hline $\begin{array}{l}\text { Limited } \\
\text { ankle dorsi- } \\
\text { flexion }\end{array}$ & $\begin{array}{l}\text { Having lack of or limited amount of dorsiflexion } \\
\text { at the ankle joint }<10^{\circ} \text { of ankle dorsiflexion [22] }\end{array}$ \\
\hline $\begin{array}{l}\text { Subtalar } \\
\text { Joint }\end{array}$ & $\begin{array}{l}\text { Responsible for inversion and eversion move- } \\
\text { ments in the frontal plane that should be in a } \\
\text { range of motion with the ratio of } 2: 1 \text { ( } 20^{\circ} \text { to } \\
\left.10^{\circ}\right) \text { if there is a good range of motion [23] }\end{array}$ \\
\hline $\begin{array}{l}\text { Midtarsal } \\
\text { joint }\end{array}$ & $\begin{array}{l}\text { Consisting of the talonavicular and the calca- } \\
\text { neocubiod joints and has two axes of rotation, } \\
\text { the oblique and the longitudinal being classified } \\
\text { as mobile or limited [24]. }\end{array}$ \\
\hline
\end{tabular}

Table 1: Definition used throughout this study as per literature.

ation if present. Consequently, an experienced clinician assessed the participants' feet as per protocol below.

\section{Assessment for digital deformities}

Participants were observed for HAV using the Manchester scale, a previously validated tool, to classify the stage and extent of the deformity present. This was classified from zero to three, with zero 
indicating no deformity and three indicating a severe deformity [14].

Lesser toe deformities were also assessed and recorded. These deformities were noted if any of the digits had a form of abnormality with the most common digital deformities noted being claw toe, mallet toe and hammer toe. Additionally, observation was carried out for prominent metatarsals, i.e., having a metatarsal bone more plantarflexed when compared to the others. The presence of deformity was noted as per literature (Table 1).

\section{Assessment of joint ranges of motion (non-weight bearing)}

A biomechanical assessment was performed to assess other foot deformities. The motion of the first ray was calculated by grasping the metatarsal heads by using a lumbrical grip to stabilize the $2^{\text {nd }}$ to $5^{\text {th }}$ metatarsal heads and then moving the ray up and down to test the motion of the $1^{\text {st }}$ ray. Additionally, the range of motion of the hallux was checked bilaterally. In such case a bisection of the proximal interphalangeal joint was performed and another bisection on the $1^{\text {st }}$ ray. One arm of the goniometer was placed on such bisection and the other on the proximal interphalangeal joint. The hallux was pushed upwards and the measurement was noted as per normal clinical practice. Limitation of hallux dorsiflexion (hallux limitus) was noted if there was $<40^{\circ}$ of dorsiflexion movement. Likewise, hallux rigidus was diagnosed if no dorsiflexion at the first metatarsophalangeal joint was noted.

For assessment of the subtalar joint, the participant was placed in a prone position. The lower one third of the lower limb and the heel were bisected and one arm was put on the bisection of the lower one third and the other was put on the bisection of the heel. The foot was inverted and everted and the measurement was noted.

The ankle joint was assessed with the participant in a supine position, in such case the lateral aspect of the lower one third of the lower limb was bisected, the foot was put in subtalar joint neutral position and one arm of the goniometer was placed on the bisection while the other was put alongside in border of the plantar aspect of the foot with the knee extended. The measurement was noted. The same procedure was repeated with the knee in flexion.

The midtarsal joint was assessed by holding the calcaneus in one hand and the distal foot with the other and used it to rotate the forefoot into supination and pronation [15].
All tests were repeated 3 times and a mean of the result was tablulated into a Microsoft Excel datasheet, which data was later analyzed in SPSS version 27. The chi-square test was used to determine the relationship between foot deformities and foot posture with ulceration.

\section{Results}

100 participants (200 limbs) were recruited, 47\% male, 53\% female. Mean age was 68.77 ( \pm 10.305 ) years, mean age for Group A was 68.22 ( \pm 10.078 ), for the no ulceration group (Group B), $69.32( \pm 10.601)$ years. Duration of diabetes for those in Group A was $18.42( \pm 10.162)$, for Group B was $17.36( \pm 11.725)$. The mean HbA1c level for Group A was $7.88( \pm 2.413)$, whilst that for Group B was 7.54 ( \pm 2.212$)$.

The site of ulceration within the ulceration group $(n=50)$ are reported in figure 1 . The most common site of ulceration was at the apex of the $2^{\text {nd }}$ digit (26\%) and the least common site was at the apex of the $4^{\text {th }}$ digit (6.0\%). Out of all patients assessed there were no ulcers in the midfoot or rearfoot region. One may note that $68 \%$ of all ulceration involved the digits, whilst 32\% involved the region of the plantar aspect of the $1^{\text {st }}$ and $5^{\text {th }}$ metatarsophalangeal joints.

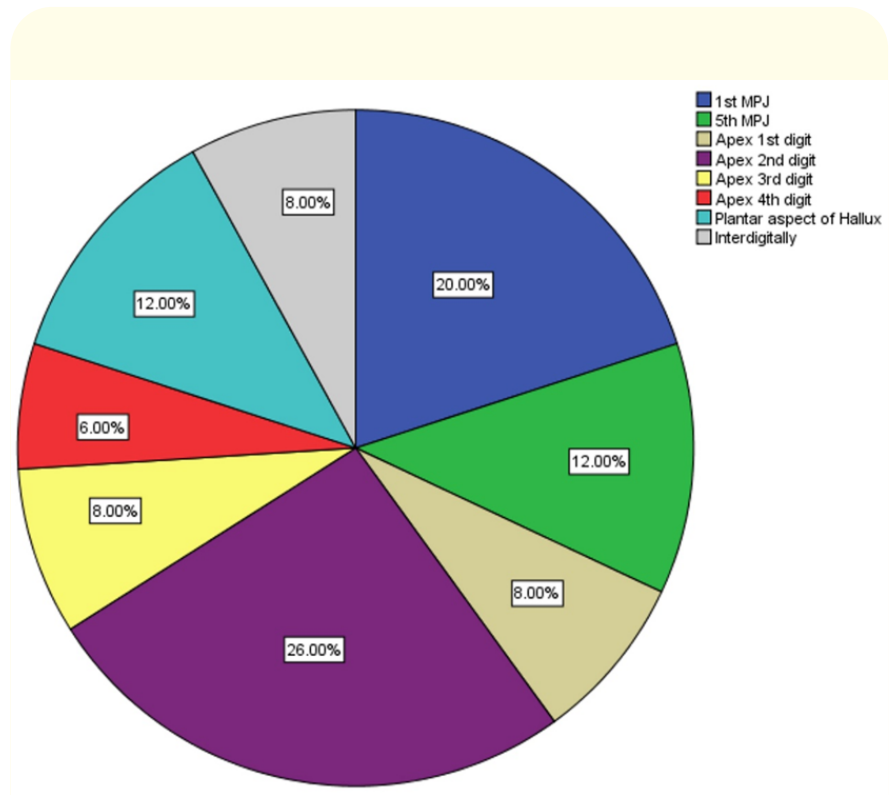

Figure 1: Sites of ulceration within the ulceration group. 


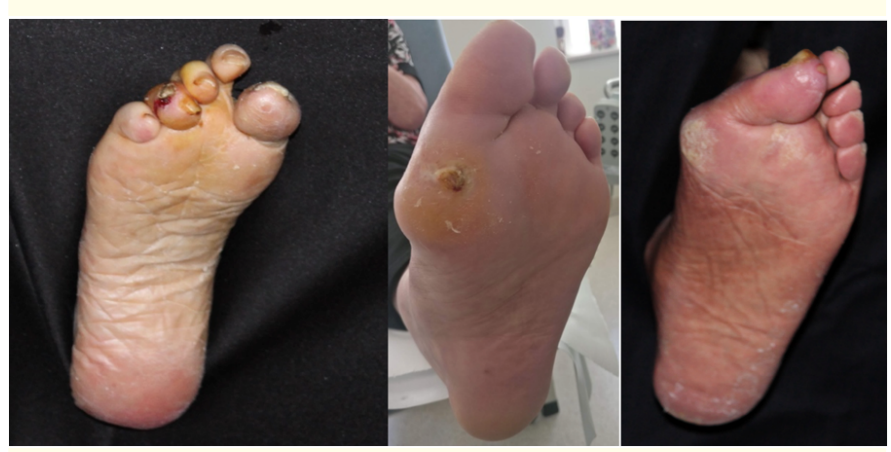

Figure 1: Typical forefoot deformities, including hallux abducto valgus and hammer toes resulting in DM ulceration.
There is larger percentage of patients with ulceration with claw toe on the $2^{\text {nd }}, 3^{\text {rd }}$ and $4^{\text {th }}$ digits right $(32.0 \%, 28.0 \%$ and $26.0 \%$ respectively) compared to patients with no ulcerations on the right foot $(12.0 \%, 14.0 \%$ and $12.0 \%$ respectively) (similar pattern on left foot). The difference between these percentages is significant since the $p$-value for the right $(0.016,0.046$ and 0.032 respectively) and left foot $(0.009,0.032$ and 0.027 respectively) is less than 0.05 level of significance.

Similarly, there is larger percentage of patients with ulceration with hammer toe on the $2^{\text {nd }}, 3^{\text {rd }}$ and $4^{\text {th }}$ digit $(50.0 \%, 38.0 \%, 22.0 \%$ respectively) compared to patients with no ulcerations on the right foot $(26.0 \%, 12.0 \%, 2.0 \%$ respectively) (similar pattern in the left foot). The difference between these percentages is significant since

\begin{tabular}{|c|c|c|c|c|c|}
\hline \multirow[t]{2}{*}{ Deformity } & \multicolumn{2}{|c|}{$\begin{array}{l}\text { Ulceration group } \\
\text { number of ulcers }\end{array}$} & \multicolumn{2}{|c|}{$\begin{array}{l}\text { Non-ulcerations num- } \\
\text { ber of ulcers }\end{array}$} & \multirow[t]{2}{*}{ Chi-Squared Test results } \\
\hline & Rt foot & Lt foot & Rt foot & Lt foot & \\
\hline Hallux valgus & $41(82 \%)$ & $42(84 \%)$ & $29(58 \%)$ & $29(58 \%)$ & $\begin{array}{l}\text { Rt: } X^{2}(3)=19.373, p<0.001 \\
\text { Lt: } X^{2}(3)=29.922, p<0.001\end{array}$ \\
\hline Claw toe $2^{\text {nd }}$ & $16(32 \%)$ & $17(34 \%)$ & $6(12 \%)$ & $6(12 \%)$ & $\begin{array}{l}2^{\text {nd }} R=X^{2}(1)=5.828, p=0.016 \\
2^{\text {nd }} L=X^{2}(1)=6.832, p=0.009\end{array}$ \\
\hline Claw toe $3^{\text {rd }}$ & $14(28 \%)$ & $16(32 \%)$ & $6(12 \%)$ & $7(14 \%)$ & $\begin{array}{l}3^{\text {rd }} R=X^{2}(1)=4.000, p=0.046 \\
3^{\text {rd }} L=X^{2}(1)=4.574, p=0.032\end{array}$ \\
\hline Claw toe $4^{\text {th }}$ & $13(26 \%)$ & $15(30 \%)$ & $5(10 \%) /$ & $6(12 \%)$ & $\begin{array}{l}4^{\text {th }} R=X^{2}(1)=4.574, p=0.032 \\
4^{\text {th }} L=X^{2}(1)=4.882, p=0.027\end{array}$ \\
\hline Hammer toe $2^{\text {nd }}$ & $25(50 \%)$ & $26(52 \%)$ & $13(26 \%)$ & $14(28 \%)$ & $\begin{array}{l}2^{\text {nd }} R=X^{2}(1)=6.112, p=0.013 \\
2^{\text {nd }} L=X^{2}(1)=6.000, p=0.014\end{array}$ \\
\hline Hammer toe $3^{\text {rd }}$ & $19(38 \%)$ & $21(42 \%)$ & $6(12 \%)$ & $6(12 \%)$ & $\begin{array}{c}3^{\text {rd }} R=X^{2}(1)=9.013, p=0.003 \\
3^{\text {rd }} L=X^{2}(1)=11.416, p=0.001\end{array}$ \\
\hline Hammer toe $4^{\text {th }}$ & $11(22 \%)$ & $13(26 \%)$ & $1(2 \%)$ & $3(6 \%)$ & $\begin{array}{l}4^{\text {th }} R=X^{2}(1)=9.470, p=0.002 \\
4^{\text {th }} L=X^{2}(1)=7.440, p=0.006\end{array}$ \\
\hline Mallet toe $2^{\text {nd }}$ & $4(8 \%)$ & $3(6 \%)$ & $2(4 \%)$ & $2(4 \%)$ & $\begin{array}{l}2^{\text {nd }} R=X^{2}(1)=0.709, p=0.400 \\
2^{\text {nd }} L=X^{2}(1)=0.211, p=0.646\end{array}$ \\
\hline Mallet toe $3^{\text {rd }}$ & $4(8 \%)$ & $4(8 \%)$ & 0 & 0 & $3^{\text {rd }} R=X^{2}(1)=4.167, p=0.041$ (bilaterally) \\
\hline Mallet toe $4^{\text {th }}$ & $4(8 \%)$ & $4(8 \%)$ & 0 & 0 & $4^{\text {th }} \mathrm{R}=\mathrm{X}^{2}(1)=4.167, \mathrm{p}=0.041$ (bilaterally) \\
\hline Deformity $5^{\text {th }}$ digit & $4(8 \%)$ & $6(12 \%)$ & $1(2 \%)$ & $1(2 \%)$ & $\begin{array}{l}5^{\text {th }} R=X^{2}(1)=1.895, p=0.169 \\
5^{\text {th }} L=X^{2}(1)=3.840, p=0.050\end{array}$ \\
\hline $\begin{array}{l}\text { Prominent metatar- } \\
\text { sals }\end{array}$ & $31(62 \%)$ & $33(66 \%)$ & $13(26 \%)$ & $14(28 \%)$ & $\begin{array}{l}R=X^{2}(1)=13.149, p<0.001 \\
L=X^{2}(1)=14.492, p<0.001\end{array}$ \\
\hline $\begin{array}{l}\text { Hallux Limitus/rigi- } \\
\text { dus }\end{array}$ & $38(76 \%)$ & $38(76 \%)$ & $14(28 \%)$ & $15(30 \%)$ & $\begin{aligned} R & =X^{2}(2)=35.034, p<0.001 \\
L & =X^{2}(2)=29.727, p<0.001\end{aligned}$ \\
\hline
\end{tabular}

Table 2: Toe deformities. 
the p-value right $(0.013,0.003,0.002)$ and left $(0.014,0.001,0.006)$ is less than 0.05 level of significance.

These apply to all other deformities studied, with the ulceration group exhibiting significantly higher incidences of mallet toes, $5^{\text {th }}$ digit deformities, prominent metatarsophalangeal joints and hallux limitus/rigidus, as outlined in table 2.

\begin{tabular}{|c|c|c|c|c|c|}
\hline \multirow[t]{2}{*}{$\begin{array}{l}\text { Joint Limi- } \\
\text { tation of } \\
\text { Movement }\end{array}$} & \multicolumn{2}{|c|}{$\begin{array}{l}\text { Ulceration } \\
\text { Group (Num- } \\
\text { ber of ulcers) }\end{array}$} & \multicolumn{2}{|c|}{$\begin{array}{l}\text { Non-ulcer- } \\
\text { ation group } \\
\text { (Number of } \\
\text { ulcers) }\end{array}$} & \multirow[t]{2}{*}{ Chi-2 test result } \\
\hline & $\mathbf{R t}$ & Lt & $\begin{array}{c}\text { Rt } \\
\text { foot }\end{array}$ & Lt foot & \\
\hline $\begin{array}{l}\text { First Ray: } \\
\text { Limited/ } \\
\text { Rigid ROM }\end{array}$ & $\begin{array}{c}45 \\
(90 \%)\end{array}$ & $\begin{array}{c}44 \\
(88 \%)\end{array}$ & $\begin{array}{c}15 \\
(30 \%)\end{array}$ & $\begin{array}{c}16 \\
(32 \%)\end{array}$ & $\begin{array}{c}\mathrm{R}=\mathrm{X} 2(3)= \\
43.377, \mathrm{p}<0.001 \\
\mathrm{~L}=\mathrm{X} 2(3)= \\
37.051, \mathrm{p}<0.001\end{array}$ \\
\hline $\begin{array}{l}\text { Subtalar } \\
\text { Joint: Lim- } \\
\text { ited/Rigid } \\
\text { ROM }\end{array}$ & $\begin{array}{c}44 \\
(88 \%)\end{array}$ & $\begin{array}{c}47 \\
(94 \%)\end{array}$ & $\begin{array}{c}22 \\
(44 \%)\end{array}$ & $\begin{array}{c}19 \\
(38 \%)\end{array}$ & $\begin{array}{c}\mathrm{R}=\mathrm{X} 2(3)= \\
32.725, \mathrm{p}<0.001 \\
\mathrm{~L}=\mathrm{X} 2(3)= \\
40.243, \mathrm{p}<0.001\end{array}$ \\
\hline $\begin{array}{l}\text { Ankle Joint: } \\
\text { Limited/ } \\
\text { Rigid ROM }\end{array}$ & $\begin{array}{c}41 \\
(82 \%)\end{array}$ & $\begin{array}{c}44 \\
(88 \%)\end{array}$ & $\begin{array}{c}24 \\
(48 \%)\end{array}$ & $\begin{array}{c}18 \\
(36 \%)\end{array}$ & $\begin{array}{c}\mathrm{R}=\mathrm{X} 2(3)= \\
17.350, \mathrm{p}<0.001 \\
\mathrm{~L}=\mathrm{X} 2(3)= \\
30.118, \mathrm{p}<0.001\end{array}$ \\
\hline $\begin{array}{l}\text { Midtarsal } \\
\text { Joint: Lim- } \\
\text { ited ROM }\end{array}$ & $\begin{array}{c}43 \\
(86 \%)\end{array}$ & $\begin{array}{c}45 \\
(90 \%)\end{array}$ & $\begin{array}{c}15 \\
(30 \%)\end{array}$ & $\begin{array}{c}13 \\
(26 \%)\end{array}$ & $\begin{array}{c}\mathrm{R}=\mathrm{X} 2(1)= \\
32.184, \mathrm{p}<0.001 \\
\mathrm{~L}=\mathrm{X} 2(1)= \\
42.036, \mathrm{p}<0.001\end{array}$ \\
\hline
\end{tabular}

Table 3: Joint limitation of movement in the ulcerated and non-ulcerated groups.

There is a larger percentage of patients with ulceration who have limited/rigid ROM at the first Ray (42.0\%, 64.0\%, 30.0\% and $86.0 \%$ limited ROM respectively) when compared to those with no ulceration having $(2.0 \%, 12.0 \%, 6.0 \%$ and $30.0 \%$ limited respectively), with a similar pattern observed in the left foot. The difference between these percentages is significant since the p-value $(<$ 0.001 ) is less than the 0.05 level of significance.

This applies to all other joints investigated, with the ulceration group exhibiting significantly higher incidences of limitation of movement at the subtalar, ankle and midtarsal joints, as outlined in table 3 .

\section{Discussion}

This study reports a significantly higher number of deformities in the ulcer group (Group A) when compared with the non-ulcer group (Group B) - mainly hammer toes, claw toes, mallet toes, hallux abducto valgus and hallux limitus/rigidus. Group A also had more rigid feet at all the main joints of the foot; the subtalar, ankle and mid-tarsal joints. Hallux valgus was by far the most common deformity in Group A (82-84\%), although the incidence in Group B was still high (58\%). Second digit hammer toe was the most common lesser toe deformity (50 - 52\%, when compared with $26-28 \%$ occurrence in Group B); this could possibly explain the $26 \%$ apical ulceration site in this toe of this population.

All these deformities and limitations in joint movement result in significant gait changes with corresponding increase in foot pressure and possibly shear, contributing to the formation of the ulcers found in this group of participants.

Although a great number of screening guidelines emphasize the need to perform routine examination of foot deformities and limited joint mobility, they stress that there is low scientific evidence for sustaining such recommendations. This study helps to provide the necessary evidence that corroborates the claim that foot deformity and limited joint mobility are indeed import risk factors which contribute to the formation of ulceration in diabetes.

An important finding to note from this study is that $68 \%$ of ulcers were in the toes. This is an important observation, since the toes in diabetes undergo various structural changes, mainly due to glycosylation, i.e. the deposition of glucose in the soft tissues, that negatively affects the stretching characteristics of tendons, ligaments and muscles. The consequence of this limitation is toe deformity, mainly claw, hammer and mallet toe deformities that have been shown to be of a higher incidence in those participants living with ulcers (Group A). These deformities, together with the limited blood supply to the toes due to the small lumen of the digital arteries, make the toes ideal sites for ulceration once there is pressure on these sites due to footwear and/or the deformity itself.

Toe deformities are not easy to manage and, most importantly, they are often relegated as minor complaints that possibly may not be managed at all in routine clinics. Such deformities invariably lead to increased apical pressure, also resulting in the highest incidence of ulcers reported in this study, i.e. at the apex of the $2^{\text {nd }}$ digit. 
A previous study has reported the morbidity of digital ulcers once amputation becomes a necessity. This study highlights that, once a toe is amputated, revision surgery and indeed other amputations are inevitable [16].

Thus, it becomes apparent that even, seemingly 'minor' toe amputations, need to be avoided. And, following the results of this study, it is evident that the early identification and proper management of toe deformities should not be discarded as insignificant as they could clearly be the precursor to ulceration and amputation.

The authors recommend that, clinically, more attention should be given to the management of these toe deformities. There is evidence that, for example, simple silicone orthodigital appliances are effective in reducing apical pressure, especially in the $2^{\text {nd }}$ digit, when the hammer toe deformity is either flexible or rigid. Perhaps the more prodigious use of these devices should be encouraged, involving a greater involvement of foot health specialists.

Another question raised here is whether the issue of glycation can be reversed, either through therapy, surgically or pharmacologically. Are there any known methods where tissue glucose can be reduced pharmacologically? Certainly, through therapy, digital deformities, once not fixed, may be managed by.

This highlights the need for including foot deformities and foot posture as part of any screening program and should be given the necessary attention with regards to management in order to lessen the detrimental effects of these deformities on the possibilities of causing ulceration.

\section{Conclusion}

This comparative study of $50 \mathrm{DM}$ patients with ulceration has reports $68 \%$ of presenting ulcers at the toes, with $38 \%$ distributed under the $1^{\text {st }}$ and $5^{\text {th }}$ metatarsophalangeal joints. The participants with ulceration exhibited significantly more toe deformities and limited joint mobility than their counterparts. The authors recommend that more clinical attention should be devoted to the 'minor' toe deformities in order to reduce the morbidity associated with these ulcerations that frequently may result in amputation. A revision in clinical protocols and guidelines regarding the management of toe deformities and limited joint mobility should be urgently addressed in order to reduce these devastating complications arising out of these deformities.

\section{Conflict of Interest Statement}

The authors declare no conflict of interest

\section{Funding Support}

This research did not receive any specific grant from funding agencies in the public, commercial or not-for-profit sectors.

\section{Bibliography}

1. Feng $\mathrm{X}$ and Astell-Burt T. "Impact of a type 2 diabetes diagnosis on mental health, quality of life, and social contacts: A longitudinal study". BMJ Open Diabetes Research and Care 5.1 (2017): e000198.

2. Dorresteijn JA and Valk GD. "Patient education for preventing diabetic foot ulceration". Diabetes/Metabolism Research and Reviews 28.1 (2012): 101-106.

3. Singer AJ., et al. "Evaluation and management of lower-extremity ulcers". The New England Journal of Medicine 378.3 (2018): 302-303.

4. Blume PA., et al. "Diabetic Foot Ulceration and Management". In: Shrikhande G. MJ, edition. Diabetes and Peripheral Vascular Disease. Contemporary Diabetes. Totowa, NJ: Humana Press (2012).

5. Formosa C., et al. "A critical evaluation of existing diabetic foot screening guidelines". The Review of Diabetic Studies: RDS 13.2-3 (2016): 158.

6. Wu SC., et al. "Foot ulcers in the diabetic patient, prevention and treatment". Vascular Health and Risk Management 3.1 (2007): 65-76.

7. Van Schie CH., et al. "Muscle weakness and foot deformities in diabetes: Relationship to neuropathy and foot ulceration in caucasian diabetic men". Diabetes Care 7 (2004): 1668-1673.

8. Ledoux WR., et al. "Relationship between foot type, foot deformity, and ulcer occurrence in the high-risk diabetic foot". Journal of Rehabilitation Research and Development (JRRD) 42.5 (2005): 665-672.

9. Alexiadou K and Doupis J. "Management of diabetic foot ulcers". Diabetes Therapy 3.1 (2012): 4-9.

10. DeBerardinis J., et al. "Review of foot plantar Pressure-Focus on the development of foot ulcerations". The Open Access Journal of Science and Technology (2016): 4. 
11. Hingorani A., et al. "The management of diabetic foot: A clinical practice guideline by the society for vascular surgery in collaboration with the american podiatric medical association and the society for vascular medicine". Journal of Vascular Surgery 63.2 (2016): 3S-21S.

12. Clayton W and Elasy TA. "A review of the pathophysiology, classification, and treatment of foot ulcers in diabetic patients". Clinical Diabetes 27.2 (2009): 52-58.

13. Formosa C., et al. "The importance of clinical biomechanical assessment of foot deformity and joint mobility in people living with type-2 diabetes within a primary care setting". Primary Care Diabetes 7.1 (2013): 45-50.

14. Garrow AP., et al. "The grading of hallux valgus. the manchester scale". Journal of the American Podiatric Medical Association 91.2 (2001): 74-78.

15. Gastwirth BW. "Biomechanical examination of the foot and lower extremity". In: Clinical biomechanics of the lower extremities. R.L. Mosby. Missouri (1996).

16. Vassallo IM., et al. "Healing and mortality rates following toe amputation in type 2 diabetes mellitus". Experimental and Clinical Endocrinology and Diabetes 129.06 (2021): 438-442.

17. Schrier JC., et al. "Definitions of hammer toe and claw toe: An evaluation of the literature". Journal of the American Podiatric Medical Association 99.3 (2009): 194-197.

18. Ledoux WR., et al. "Clawed toes in the diabetic foot: Neuropathy, intrinsic muscle volume, and plantar aponeurosis thickness". Journal of Foot and Ankle Research 1.1 (2008): 02.

19. Coughlin MJ. "Mallet toes, hammer toes, claw toes, and corns. causes and treatment of lesser-toe deformities". Journal of Postgraduate Medicine 75.5 (1984): 191-198.

20. Durrant B and Chockalingam N. "Functional hallux limitus: A review". Journal of the American Podiatric Medical Association 99.3 (2009): 236-243.

21. Tavara-Vidalón SP., et al. "Static range of motion of the first metatarsal in the sagittal and frontal planes". Journal of Clinical Medicine 7.11 (2018): 456.

22. Petcu D and Colda A. "Foot functioning paradigms". The Publishing House Medicine of the Romanian Academy 3.14 (2015): 212-217.
23. Yates B and Merriman L. "Merriman's assessment of the lower limb". Edinburgh: Churchill Livingstone/Elsevier (2009).

24. Blackwood CB., et al. "The midtarsal joint locking mechanism". Foot and Ankle International - SAGE Journals 26.12 (2005): 1074-1080.

Volume 4 Issue 10 October 2021

(C) All rights are reserved by Alfred Gatt., et al. 